\section{MICRORADIOGRAPHY AND AUTORADIOGRAPHY}

A

SYMPOSIUM on microradiography and autoradiography was held on December 17, 1953, at the Institute of Physics, 47 Belgrave Square, London, by the Scientific and Technical Group of the Royal Photographic Society. Many modern scientific methods are intimately connected with photographic techniques, and it can be regarded as very fortunate that biological and medical research workers and photographic scientists were able to meet one another at such an occasion to discuss their methods and also their results.

The first part of the meeting was devoted to microradiography and gave evidence of the potentialities and limitations of the method. From recent physical and technical developments on $\mathrm{X}$-ray beams from very small focal spots, new possibilities may be expected. The first speaker, Prof. G. A. G. Mitchell (Anatomy Department, University of Manchester), explored the potential uses of microradiography of biological objects, such as body tissues, leaves, seeds, fibres, hairs, insects, wings, ova, small crustacea, etc. He has tried methods of enhancing contrast by using various injections and by soaking or impregnating tissues and materials with solutions which are moreor-less radio-opaque; he has also tested material with and without preliminary freeze-drying. Prof. Mitchell came to the conclusion that in most respects microradiography is less valuable than histological and histochemical methods in investigating the structure and composition of biological objects. On the other hand, the following advantages of microradiography were stressed: much thicker sections can be examined and thus the arrangement of various structures can be traced over greater distances than is possible in ordinary histological sections $5-10 \mu$ thick; structures containing bone or calcareous deposits can be examined without preliminary decalcification; normal or abnormal deposits of radio-opaque substances are readily detectable; and the distribution of vessels and tubules can be studied accurately and fairly rapidly by the method.

Mr. R. V. Ely (London) dealt almost exclusively with the requirements of apparatus such as 'sealed off' and 'demountable' X-ray tubes, backing and diffusion pumps, valves, vacuum gauges, high tension and filament supply units, mains voltage stabilizers, vacuum cassettes, etc. A demountable X-ray tube developed by Mr. Ely permits easy removal of the window in order to attach an extension cylinder holding a quarter-plate at a considerable distance from the target. The apparatus can be used for photographic as well as for direct magnification ; in the latter case only very small focal spots are permitted.

Whereas the first two speakers chiefly dealt with magnifications up to 500 times, the third speaker, Dr. V. E. Cosslett (Cavendish Laboratory, Cambridge), looked for magnifications of the order of one thousand diameters and above. He therefore prefers the term 'X-ray microscopy' to microradiography. Since the optical resolving-power is limited to about $0.5 \mu$ by the wave-length of light, a higher resolvingpower should be possible using $\mathrm{X}$-rays of a wavelength of the order of $1 \mathrm{~A}$. As the contrast attainable is roughly proportional to the cube of the wavelength of the $\mathrm{X}$-rays, practical considerations demand the use of wave-lengths of one or several angströms (that is, $12-\mathrm{kV}$. X-rays and less are required). Four basic methods of X-ray microscopy were suggested : the conventional contact method, where object and film are in close proximity; three other methods which entail direct magnification by means of curved crystals, by mirror reflexion and end-window X-ray tubes, respectively. The relative merits of these four methods were reviewed, and the end-window technique that has been developed by Dr. Cosslett was described in greater detail. It involves the production of an ultra-fine focus on an end-window target, using electron optical techniques. The use of very thin windows makes high $\mathrm{X}$-ray intensity available from spots of the order of $1 \mu$ in diameter. At present, Dr. Cosslett and his co-workers are attempting to obtain a focal spot of the order of $0.1 \mu$. High direct magnification is obtained by bringing the specimen close to the window. Several examples of Dr. Cosslett's method for examining the microstructure of biological and metallurgical specimens were shown. Photographs have been taken of living insects, in which great interest is being shown at the present time, in order to follow up radiation damage in insects when exposed to various X-ray doses.

The second part of the meeting was entirely devoted to biological autoradiography. The techniques of micro-autoradiography are mainly based on the use of stripped nuclear-track emulsions. At present the refinement of methods appears to be in the foreground of autoradiographic investigations and, in particular, a deeper insight into the problems of resolution and quantitative uptake of radioisotopes is required. Dr. S. R. Pelc (Experimental Radiopathology Research Unit, Hammersmith Hospital, London) reviewed autoradiography by discussing the possibilities and limitations of the method, the planning and design of experiments and the interpretation of the results. The incorporation of radioisotopes into chemical compounds in the organism depends on the correct choice of the chemical compound of interest and the concentration, which in turn is dependent on the sensitivity of the film material to be used. Formulæ which relate the concentration in terms of micro-curies per c.c. and of half-lives of the tracer were given. An estimate of the amount required depends also on the frequently unknown distribution within the organism. It was shown, for example, that, by administering sulphur-35 as sulphate ion, it finds its way into the cells of the cartilage of the trachea and very little is taken up by the epithelial lining. After injection of sulphur-35 as $d l$-methionine $\left({ }^{35} \mathrm{~S}\right)$, significant accumulation of the isotope is found in the epithelial cells and only a faint trace in the cells of the cartilage. In the preparation of the specimens, special care has to be taken in regard to possible loss of radioactive compounds due to solvents and also to the possibility of the formation of artefacts that are caused, for example, by chemical interaction between specimen and photographic material. Several examples of the possible ambiguity and pitfalls in interpretation were given.

Dr. L. F. Lamerton (Department of Physics, Royal Cancer Hospital, London) discussed problems involving the resolution and sensitivity in autoradio. graphy. In contrast to the theoretical treatment of resolution by Doniach and Pelc, Dr. Lamerton defines resolution as the distance $d$ if the images of two uniformly active cylindrical sources of diameter $d$ can just be resolved when the centres are separated by a distance $2 d$. A table was given showing the resolution, in terms of microns, obtainable theoretically for various emulsion and specimen thicknesses 
and for various distances between specimen and film. In addition there are two further factors which limit the high resolution otherwise attainable. These are the unavoidable background due to chemical fogging and cosmic rays, and the cross-fire of radiation from surrounding parts of the specimen. With reasonable precautions, the background may be reduced to about 4 grains/100 $\mu^{2}$ or less. From a theoretical treatment of the cross-fire radiation (based on $a_{0}$ relation between grain density and distance from a point source), it is shown that an autoradiograph will be recognizable above a structure of cellular dimen. sions only if the concentration of the activity within the structure is a number of times greater than that of the surrounding specimen. This concentration must be higher for long-range electrons, that is, greater with phosphorus-32 than with sulphur-35 or carbon-14. Dr. Lamerton referred also to a new Kodak X-ray stripping-plate which fills the gap in sensitivity and resolution between the fast $X$-ray film and the relatively slow nuclear-track stripping-plate.

Dr. L. G. Lajtha (Radiotherapy Department, Churchill Hospital, Oxford) described a highresolution autorediographic stripping-film technique adapted to smears made from human bone-marrow cultures in vitro. In such a smear the cells are separated sufficiently from each other to prevent 'crossfire', and good results have been obtained by floating the emulsion at $25^{\circ} \mathrm{C}$. on distilled water for 4-6 min. The autoradiographs were stained after processing to facilitate recognition of the individual cells. The method is sensitive enough to detect and localize as little as 20-30 phosphorus-32, or 30-50 sulphur-35, a.toms per cell.

Experiments on the mechanism of deoxyribonucleic acid synthesis as measured with phosphorus-32 and adenine $\left({ }^{14} \mathrm{C}\right)$ were described. Experiments on sulphate $\left({ }^{25} \mathrm{~S}\right)$ uptake have shown that uptake of inorganic sulphate $\left({ }^{35} \mathrm{~S}\right)$ and its incorporation into $\mathrm{a}$ substance related to the chondroitin sulphates is a specific function of the myeloid cells in the bone marrow.

\section{THE BOSE INSTITUTE, CALCUTTA}

HE thirty-sixth anniversary meeting of the Bose Institute took place on November 30,1953 , when Dr. N. K. Bose, director, River Research Institute, delivered the sixteenth Acharya Jagedish Chandra Bose Memorial Lecture on "The Role of Silt and Sand in Multipurpose River Valley Projects".

Dr. D. M. Bose, director of the Bose Institute, in presenting his report on the working of the Institute for the past year, said that completion of many important projects commenced during the past few years was being delayed for want of funds. $\mathrm{H}_{\Theta}$ mentioned that early this year the Institute had acquired a plot of forty bighas of good agricultural land at Shamnagar, near Barrackpur, for erection of an experimental station for certain fundamental investigations in plant sciences which the Institute proposes to undertake. The Institute had to obtain $\mathbf{a}_{\mathbf{b}}$ loan of Rs. 60,000 for this purpose. For the erection of necessary residential quarters and laboratory buildings and for electric installation and for fencing the estate about Rs. I lakh will be required.

The investigations which the Institute has been carrying out during the past few years on the action of X-radiation in producing mutations in a few economic plants have obtained a certain amount of recognition, and the Institute has, on invitation from the National Institute of Sciences of India, submitted a five-year scheme, which may be extended by another five years, of fundamental investigations on the mutagenic action of different kinds of radiations on plants. The latter will be selected mainly for their suitability for genetic studies.

Preliminary investigation 3 started during the past year have disclosed that the beta-radiation from radioactive phosphorus, which is selectively absorbed in plant nuclei, is a very convenient tool for inducing mutation in plants ; for example, with this method, new types of effects are being obtained in certain varieties of jute plants in addition to those obtained with the same kind of plants after irradiation trials with X-rays extending over many years.

At Mayapuri, Darjeeling, a plant pathological laboratory was begun about three years ago as an experimental measure. Already valuable work has been started on the breeding of new hybrids of potatoes resistant to several virus and fungal infestations, using locally available potatoes as one of the parents and imported resistant strains as the other. This work is being undertaken in co-operation with the West Bengal Seed Potato Farm at Rungbul, near Darjeeling. The Institute has' already done some good work in detecting the presence of potato wart disease, hitherto not known to occur in India, in one of the plots at Rungbul sown with an imported variety of potatoes known as Furore. This observation when published in Science and Culture attracted the attention of the Ministry of Agriculture, Delhi, and resulted in a visit to Darjeeling of the director of potato research and the deputy director of plant protection for inspection of control measures. Studies of other potato disease of bacterial origin have resulted in the receipt for examination from different parts of India of similar infected potato tubers. Without more financial assistance the Institute cannot indefinitely maintain the Plant Pathological Laboratory, which will be compelled to close.

Mayapuri is also being developed as a centre for cosmic ray research. On a request from the Council for Scientific and Industrial Research, India, a scheme with detailed plans and estimates for erection of a laboratory and workshop for -cosmic ray research has been submitted. There will also be accommodation for guest workers who may come to Mayapuri for cosmic ray work.

The Institute has received a new grant from the Board of Research on Atomic Energy for investigations on the use of radioactive isotopes of carbon and phosphorus for studying photosynthesis and the mutagenic action of beta-rays of phosphorus. In a recently formulated five-year plan of research the Institute has included a proposal for the study of photosynthetic utilization of solar rays as a method for food and power production and of its economic feasibility.

The microbiology department has received a grant from the Council for Scientific and Industrial Research, India, for the production of antibiotics isolated from Streptomyces spp. which has some remarkable bactericidal properties.

Besides these new schemes, the Institute is continuing to receive the usual grants-in-aid from the Board of Research on Atomic Energy, the Central Jute Committee, the Central Oil Seeds Committee, the Cotton Committee of West Bengal, I.C.A.R. grant for weed control, and the B.O.C. grant for palæobotanical research. 